\title{
Action Research Using a Chinese Career Model Based on the Wisdom of Classic of Changes and its Applications
}

\author{
Shu-Hui Liu, ${ }^{1}$ Chih-Hung Wang, ${ }^{1}$ Chi-Ping Deng, ${ }^{2}$ Foo Bee Keh, ${ }^{2,3}$ Yi-Jen Lu, ${ }^{4}$ and Ya-Chi Tsai ${ }^{5}$ \\ ${ }^{1}$ Department of Guidance \& Counseling and Chinese Career Research Center, National Changhua University of Education, \\ Changhua, Taiwan \\ 2 Department of Guidance \& Counseling, National Changhua University of Education, Changhua, Taiwan \\ ${ }^{3}$ Counseling Center, New Era College, Kajang, Malaysia \\ ${ }^{4}$ Bureau of Education, Tainan City Government, Tainan, Taiwan \\ ${ }^{5}$ Mental Health Research and Education Center, Shanghai Ocean University, Shanghai, China
}

\begin{abstract}
To challenge the Taiwan Ministry of Education's (TMOE) dominant enforcement of a personenvironment fit model, the Chinese Career Research Center incorporated yin-yang alternation principles from the Classic of Changes ( I Ching, Yi Jing or 易經) to develop the model of career development touching the sky yet grounded (TSG) and corresponding practice guidelines, a career website (CCN), and four career service projects. Using Lewin's (1946) cyclical-spiral process of action research, CCN and TSG service projects were promoted to complement the TMOE's fit model, and feedback was utilised to revise our TSG model and its applications. Yin-yang alternation principles and the four stages of chien (the creative) from the Classic of Changes were applied to develop social action strategies. Social change was indicated by counsellors' and students' changes in their career views, as well as the TMOE's direct financial support for TSG service projects. This progress is encouraging for whoever is interested in developing culture-inclusive indigenous psychology with practical outcomes.
\end{abstract}

Keywords: career development, career counselling, Chinese philosophy, Classic of Changes (Yi Jing), indigenous psychology

\section{Social Problems and Research Purposes}

In this fast-paced world, change has become the only certainty in most people's career path. Both Miller (1995) and Trevor-Roberts (2006) point out that the career congruence model from modernism has limitations in coping with career uncertainty. Empirical evidence supports how individuals' career development has been gradually shifted from a traditional linear pattern to boundaryless/protean patterns (Bussolari \& Goodell, 2009; Forrier, Sels, \& Stynen, 2009; Harrison, 2006; Stoltz, Wolff, Monroe, Mazahreh, \& Farris, 2013), within which certainty and perceived continuity needed to be constructed by recognising or appreciating change (Adams, 2006; Pryor \& Bright, 2003a). Career development has been reframed as a process of choosing an educational or occupational route for 'identity investments' (Wijers \& Meijers, 1996).

Meanwhile, the Taiwan Ministry of Education (TMOE) has been promoting a focus on higher education's function in vocational practicality in training to meet the job market's needs (學用合一). The TMOE has also sponsored a career website, the Career and Competency Assessment Network (UCAN), and enforced its use in all colleges and universities in Taiwan. Additionally, employability has been listed as one criterion to evaluate the performance of colleges/universities; hence, many colleges/universities have revised their academic curriculum to meet the job demands of business and industry. As a result, college-level academic teaching has in some ways become job skill training. The focus of college career assistance has also dramatically shifted from career exploration and development to vocational decision-making and employability enhancement.

A similar TMOE policy has been enforced in secondary schools. All junior high students' aptitude and vocational interest tests results, along with academic performance records, have been recorded in the 'little blue booklet' (小藍本). TMOE's policy of talent development (適性揚 才) has requested senior high school recruitment to be 
designed in a way to favour junior high students applying for senior high school programs congruent with their test results. As a result, students, their teachers and parents have been disciplined by TMOE's policy to affirm that only those numbers in the TMOE's little blue booklet mattered in their educational selection process.

These TMOE policies seem to emphasise rational decision-making to achieve a higher degree of personenvironment fit (Spokane, Meir, \& Catalano, 2000; Tinsley, 2000; Tracey, Darcy, \& Kovalski, 2000). According to Miller (1995) and Trevor-Roberts (2006), this will not prepare individuals to adapt to today's rapidly changing job environment. By not addressing uncertainty, such a policy might create irrational tension and frustration (Bardi, Guerra, \& Ramdeny, 2009; Bredemeier \& Berenbaum, 2008).

To challenge those TMOE policies and address career issues in a changing world, the Chinese Career Research Center proposed an alternative model to capture the dynamic nature of career development. Called the model of career development touching the sky yet grounded (TSG model; 頂天立地模式), it is based on yin-yang alternation principles from the Classic of Changes (易 經; also known as the I Ching, Yi Jing or the Book of Changes, an ancient divination text and the oldest of the Chinese classics), which teaches people how to deal with an ever-changing world. During the past 4 years, we have developed this model and its applications, including practice guidelines (TSG guidelines), a website (Chinese Career Net [CCN]; http://careering.heart.net.tw/) and TSG service projects. Our intent was to echo Hwang's $(2005,2012)$ advocacy for culture-inclusive psychology and Liu, Ng, GastardoConaco, and Wong's (2008) proposition for social and cross-cultural psychology as a global enterprise involving action research.

The purpose of this action research was to complement TMOE's fit model with our TSG model and its applications. The problem with the TMOE's fit model did not lie in the model itself, but in the dominant enforcement of the model. The fit model definitively has its merits, which is why it has survived for more than a century. Nevertheless, the fit model also has its limitations, especially in this postmodern ever-changing world. With the dominance of those TMOE policies, there was little room for any other career model or website to complement the TMOE's fit model and the UCAN. Our very first task was to find room and funding for our model and its applications; and, then, to find out ways to deliver services for students' benefit.

This article will demonstrate our success at challenging the TMOE's domination over career services and education in Taiwan. It presents the following: (1) emerging trends in the career literature and development of our TSG model and its applications; (2) research methods, to describe our actions from the perspective of research design; (3) research results, consisting of three parts, including actions and effective social action strategies from the Classic of Changes, functions of the CCN, and the effectiveness of this research; and (4) the future vision of $A$ Host of Dragons without any Leader (群龍無首).

\section{Literature Review Emerging Trends in the Career Literature}

A career view is how an individual views and copes with his or her career issues, and it consists of career visions and projecting strategies as ways of being-in-the-world (Liu, S., 2005). Career vision identifies what an individual wants in his or her career; in other words, it could be chosen goals, directions for his or her career, or delineated or portrayed pictures of ideal lives. Projecting means to cast a career plan. Such a plan helps an individual to work out what could or should be done. Projecting strategies identify how an individual gets what he or she wants from what he or she is given. Such strategies relate to the ways individuals deal with three types of career issues: making a career choice, actualising a career vision, and dealing with career uncertainty. Everyone has his or her own career view, which indicates his or her ideal career development and favoured career development strategies.

A person-environment fit paradigm considers a matched job as the ideal career development and favours rational strategies toward job security. It proposes three broad factors as the core of career development: (1) a clear understanding of oneself; (2) knowledge of the requirements and conditions for success in different lines of work; (3) true reasoning on the relationship between an individual and work. Such an approach considers career uncertainty as something bad and tries to avoid it. This approach has been dominant in the field of career development for decades (Spokane et al., 2000; Tinsley, 2000; Tracey et al., 2000).

Nevertheless, other Western postmodern career theories have appeared, in line with Miller's (1995) and TrevorRoberts's (2006) arguments for needing positive reactions to career uncertainty; including Gelatt's positive uncertainty theory (Gelatt, 1989, 1991a, 1991b, 1992, 1995; Gelatt \& Gelatt, 2003), Krumboltz's planned happenstance theory (Krumboltz, 2009; Mitchell, Levin, \& Krumboltz, 1999), and Pryor and Bright's career chaos theory (Bright \& Pryor, 2005, 2007; Pryor, 2007; Pryor, Aniundson, \& Bright, 2008; Pryor \& Bright, 2003a, 2003b, 2004, 2005, $2006,2007,2008,2009)$. These career theories have identified adapting and awareness strategies toward openness and exploration as preferred career projecting strategies, and consider career uncertainty as something positive.

Such an emerging trend in Western career literature indicates the existence of two career projecting strategy prototypes: (1) rational strategies toward security and (2) adapting strategies toward exploration. These two prototypes were also supported by empirical evidence in Taiwan (S. Liu, 1999; S. Liu \& Chu, 1999). Also, in a New Zealand study, security and exploration were 
identified as two core values underlying ideal career visions and projecting strategies (Vaughan \& Roberts, 2007).

More interesting was that each prototype had been found to have both positive and negative effects on career development (Hsiao, 2006; Kao \& S. Liu, 2012; Lee, 2010; Liu et al., 2013; Mendes \& Moslehuddin, 2006; Peng, Hung, Lin, \& Liu, 2013; Peng, Hung, \& S. Liu, 2013; Reindal, 1999; Samuels \& Pryce, 2008). Also, these two prototypes are not mutually exclusive, as they can nurture each other and bring out fluidity. Career explorers who flexibly utilise both strategies may possess resilience, passion, and wellbeing throughout their career development (Hsiao, 2006; Kao \& Liu, S., 2012; Lee, 2010; Peng, Hung, \& S. Liu, 2013; S. Liu et al., 2013). Such a phenomenon is congruent with the yin-yang thinking of ancient Chinese cultures. Therefore, the Chinese Career Research Center adapted the yin-yang alternation principles of the Classic of Change to further elaborate these two prototypes.

\section{Theoretical Foundation: the TSG Career Development Model}

Yin and yang are two essential elements of the Classic of Changes, which consists of 64 hexagrams. A hexagram is a figure composed of six stacked horizontal lines, where each line is either yang (an unbroken, or solid line) or yin (broken, or an open line with a gap in the center). Yin represents receptivity and denotes the power of the earth; individuals in accordance with yin kindly support all kinds of men and things with their great virtue. Yang represents creativity and denotes the power of heaven; individuals in accordance with yang unceasingly strive to improve themselves with their great perseverance. Both yin and yang possess the characteristics of originating, penetrating, benefitting, and rightful-doing. Their combinations and alternations constitute 64 hexagrams, which denote appropriate action strategies in various situations. The yin-yang alternations show the relationships of $m u-$ tual completion and enhancement (亦此亦彼), generation by opposition (陰陽轉化), and joint production (生生不 息). These principles govern, create, and transform all things existing in between earth and heaven (Chen, 2002; Cheng, 2009; L. Fu, 1981; P. Fu, 2011; Huang, 2003, 2007; Y. Liu, 2005; Nan, 1991a, 1991b).

The person-environment fit paradigm emphasises the strategy of choosing and controlling (精挑掌控), which is symbolised by the white of the yin-yang tai ji (太極) diagram (Figure 1). The white body of a fish on the right side represents yang or proactive career actions, that is, all kinds of career creations, which result in career achievements. Meanwhile, the white eye of the black fish on the left side represents the fundamental yang intention to control one's career path. However, the extreme turns yang into yin, the black body; that is, the yang intention of controlling one's career ( $y$ in actions) may lead to following planned career paths submissively.

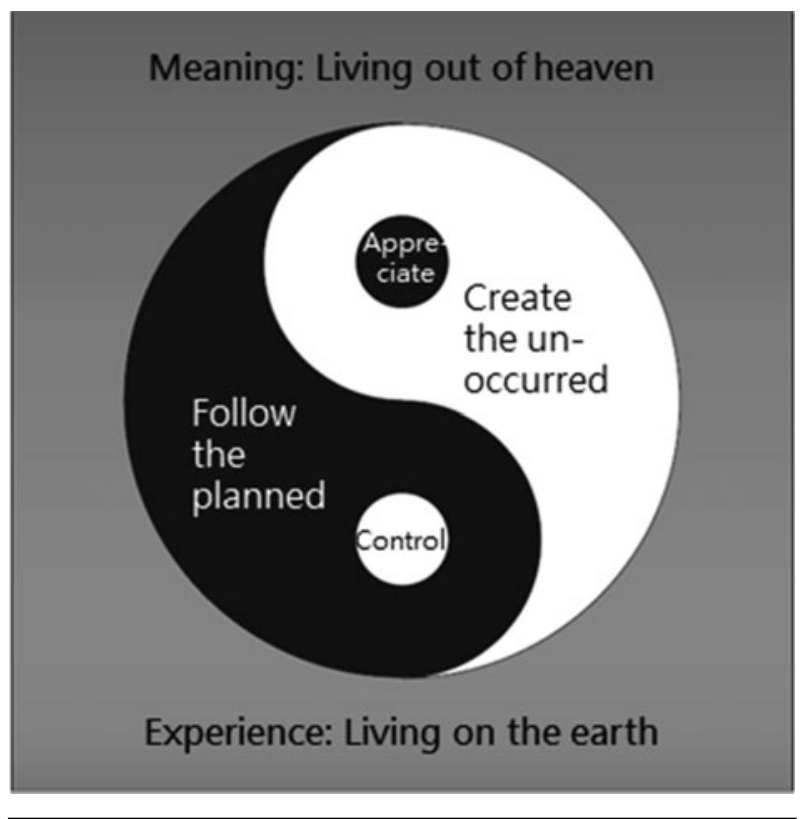

\section{Figure 1}

The model of career development, touching the sky yet grounded. Note: Strong controlling turns into following the planned. Strong adapting turns into creating the un-occurred. Career development is twofold: one is experience, as living on the earth, and the other is meaning, as living out of heaven.

Postmodern career theories emphasise the strategy of appreciating and adapting (悅納變通), which is symbolised by the black of the yin-yang tai ji diagram. The black body of the fish on the left side represents receptive career actions, which results in career development in harmony with an individual's surroundings. The black eye of the white fish on the right side represents the basic yin intention to follow, with curiosity and appreciation about whatever presents itself. With adventurous exploration, an individual can open up new career opportunities. This may turn yin's adaptation intention into yang's creativity actions, the white body.

Figure 1 portrays two projecting strategy prototypes and the career development process resulting from these (S. Liu \& Wang, 2014). Doing the right thing at the right time (適時而動) is the core principle underlying the 64 hexagrams of Classic of Changes (Nan, 1991a, 1991b). Hence, yin strategies are to roll with the punches (順勢而為) and yang strategies are to guide a trend along its natural course of development (因勢利導). Summative career development results from wisely applying $y$ in and yang strategies to whatever one encounters. The yin intention of appreciating might turn into creating the un-occurred; meanwhile, the yang intention of controlling underlying creation might induce following the planned. In turn, the yin intention of appreciating underlying following might turn into creation. As a result, the the yin-yang tai ji diagram becomes an unceasingly running circle portraying the characteristics of mutual completion and enhancement, generation by opposition, and joint production in career developing. As mentioned above, those who flexibly utilise both strategies 


\begin{tabular}{|c|c|c|}
\hline \multirow[b]{2}{*}{ Career praxis } & \multicolumn{2}{|c|}{ Projecting strategy } \\
\hline & Choosing and Controlling & Appreciating and Adapting \\
\hline \multicolumn{3}{|l|}{ Method of praxis } \\
\hline Exploration mechanism & (Left-brain) rational analysing & (Right-brain) intuitive creating \\
\hline Acceptable options & Narrowing down & Opening up \\
\hline Self-exploration method & Objective quantitative assessment & Subjective qualitative assessment \\
\hline Environmental exploration method & Non-involved information processing & Involved information experiencing \\
\hline Unfolding styles & Focus and controlling & Open and appreciating \\
\hline \multirow[t]{2}{*}{ Unfolding capacity } & Analytical controlling & Flexibly adapting \\
\hline & Resilience from stress & Pursuing meaning with hope \\
\hline \multirow[t]{2}{*}{ Career belief regarding learning and working } & Practicality purpose of learning & Humanity purpose of learning \\
\hline & Qualification for job & Adjustment for job \\
\hline \multicolumn{3}{|l|}{ Goals of praxis } \\
\hline Ultimate concerns & Controlling to stabilise & Adapting to change \\
\hline Person-environment relationship & Promoting agency & Promoting person-environment harmony \\
\hline
\end{tabular}

may possess resilience, passion, and wellbeing throughout their career development (Hsiao, 2006; Kao \& S. Liu, 2012; Lee, 2010; Peng, Hung, \& S. Liu, 2013; S. Liu et al., 2013). The resulting career development is twofold: one part is experience, as living on the earth (活在世間), and the other part is meaning or cultivation, as living out of heaven (活出天道).

\section{Theoretical Application: TSG Practice Guidelines}

The TSG guidelines were derived from our TSG model. The goals of the TSG guidelines are to assist individuals in: (1) establishing their ideal career visions, and (2) practising and applying both projecting strategies wisely. As to career vision, what one wants and what one can do are two crucial dimensions to be explored. The wants dimension relates to vocational interests, work and/or life values, and work style; and the can do dimension relates to abilities, knowledge, and skills. It does not matter whether one is a business owner or an employee, everyone is encouraged to creatively design his or her ideal job, rather than being passively matched to the jobs that have been designed by others. Even for the same job, people can do it in different ways and express themselves differently.

As to projecting strategies, both prototypes should be applied to the career praxis. Table 1 denotes the relationship between career praxis and projecting strategy in terms of methods and goals (S. Liu \& Wang, 2014). The strategy of choosing and controlling emphasises rational analyses to find a precise understanding of self and environment, by utilising quantitative assessment results and factual career information. The strategy of appreciating and adapting emphasises the intuitive openness to obtain an experiential understanding of self and environment, by becoming immersed in narratives or art creation (see J. Liu, this volume). An effective career praxis involves: (1) using both yin and yang strategies; (2) using them interactively and flexibly; (3) wisely and creatively integrating products or insights from the previous two (S. Liu, Chen, Lu, Lu, \& Ching, 2014).

Taken together, for self-exploration, individuals first take tests and receive numerical feedback in order to understand the objective parts about themselves and/or their environments (choosing and controlling); then, via drawing, narration or some sort of creative art, they recall corresponding lived experiences and personal meanings attached to the objective parts in order to experience intensive and embodied feelings (appreciating and adapting). Later, via self-ratings, naming or some sort of creative art, individuals make a synthetic identification based on products or insights from the previous two types of explorations (integration).

Another activity of synthesis between positives and negatives gives a clearer example of applying yin-yang alternation principles. The first step is to generate a set of positives and negatives. This can be used to examine the positives and negatives of one's ideal career vision, the likes and dislikes of an occupation, the costs and rewards of a choice, the individual preferences and environmental demands of a situation, and so on (choosing and controlling). The instruction given is 'to draw an integrative picture (1) with a theme, (2) using each of those positives and negatives, and (3) reflecting a career vision/occupation/choice/situation you like from the bottom of your heart'. After completing these appreciating and adapting and integrating parts, career explorers tell the stories of their pictures, drawing out implications for dealing with career issues in real life, and finally make an action plan (choosing and controlling).

The abovementioned activity can be strengthened if it is followed by practice of projecting activities to stimulate both yin and yang strategies. Here is an example: The first step is to have individuals/authors draw or narrate their self-identifications or ideal career visions and discuss how they like their pictures or narratives (choosing and controlling). Next, the authors' partners/others add destroyers into the pictures or narratives. The authors are instructed to appreciate the unexpected surprise given by 
others (appreciating and adapting). More importantly, authors are encouraged to actualise their existential freedom to make their pictures or narratives to become their own (integration). Authors are invited to give a name for their projecting strategies so that the strategies have personal meanings. Finally, authors are asked to narrate their revised pictures or narratives and reflect on how they can apply their learning from this activity to career projecting in real life (choosing and controlling).

\section{Research Method}

\section{Research Framework and Process}

The Chinese Career Research Center utilised a practical view of constructive realism (Hwang, 2013a, 2013b) to match Atsumi's quantitative-qualitative twin wing approach (2007), and follows Lewin's (1946) top-down model of action research. There were three stages in Lewin's action research. For this 4 -year research as a whole, the first $2 \frac{1}{2}$ years were a planning stage; each of the next three semesters, with two or three projects running at the same time, started with action and ended with evaluation. Those major stages constituted a cyclical-spiral process. Also, for each project in this research, there was a minicyclical-spiral process of planning, action, and evaluation as well.

In the major planning stage, we proposed our TSG model as the theoretical foundation for this research. This model echoed Hwang's (2012) advocacy for cultureinclusive psychology by incorporating the wisdom from the Classic of Changes to come up with a workable framework that emphasised both the control and appreciation nature of career development. Subsequently, the TSG guidelines were derived from our TSG model, and the first version of the CCN was constructed, based on our TSG model and guidelines.

In the major action stage, first we received grants from our university (NCUE) to develop an initial TSG service project, using $\mathrm{CCN}$, for our university; later, three more TSG service projects led by local practitioners were designed for Tainan junior high schools and other universities in Taiwan. During the major evaluation stage, we used the feedback from coordinators and participants to evaluate the effectiveness of projects and make adjustments to our TSG model, TSG guidelines, and the CCN.

Our research process followed four stages of chien (乾 卦, the creative force) in the Classic of Changes: hidden dragon (潛龍, not being seen), visible dragon (見龍, being seen), diligent dragon (愓龍, working hard to excel), and jumping dragon (躍龍, evolving to be great). Details of this process will be presented in the results section.

\section{Research Projects and Participants}

There were eight projects in this 4 -year research. Table 2 lists basic information about each project. The Chinese Career Research Center, a centre sponsored by our university to develop indigenous career theory, practice, and re- sources, was in charge of the research. The first five projects (I-1, I-2, II-1, II-2, III-1) were undertaken at our university. Major coordinators were other offices or departments on campus. The first two projects were research-oriented. Participants were students and alumni. All of the students and alumni in our pools were invited via email and telephone, and $96.88 \%$ and $28.76 \%$ responded, respectively. Projects II- 1 and II- 2 were resource-oriented. Participants of project II-1 were career experts invited from various Taiwanese universities. Participants of project II-2 were executives of our university, who attended our explanation sessions.

The remaining four projects were service-oriented. The III-1 project recruited participants via free registration, and 106 students attended. The last three projects reached out from our university: the III-2 project for Tainan junior high schools and the IV-1 and IV-2 projects for other Taiwanese universities. The last three projects were also training-oriented; that is, we provided professional training for practitioners and they delivered the TSG services in their fields. In the III- 2 project, in the first year, our coordinator requested all the school counsellors and students in our polls to join, and the response rate was close to $100 \%$; in the second year, we suggested recruiting volunteers instead, and about 50 school counsellors attended our training. Both the IV-1 and IV-2 projects recruited volunteers.

\section{Evaluation}

Effects of this action research were examined using Liu et al.'s (2008) principles of interconnectedness. While most Western action research uses the term democracy to highlight their equality and participation features, Liu et al. advocated the term interconnectedness instead, to identify action researchers' 'managing contradictions, tolerating deeper elements of paradox, and synthesizing the beauty of complex patterns' (2008, p. 1170). They argued that 'an Asian epistemology for action research puts the principles of interconnectedness, li-i-fen-shu (理一分殊, one principle, many manifestations) and tien-jen-ho- $i$ (天人合一, heaven and humanity in union) at the heart of the research process' (p. 1171). Their proposition was adopted since it is congruent with the yin-yang alternation principles applied in this study.

Their five interconnectedness indexes were adapted in this research, including: (1) acquiring feedback in a cyclical-spiral process of planning, action, and evaluation; (2) social relation-building to plant seeds in different social positions for future actions; (3) reflexivity of participants in terms of increasing awareness of how they can deal with career issues differently; (4) empowerment by providing training, opportunities, and resources for career explorers and career services practitioners; and (5) social changes in terms of reducing TMOE's domination over career services and education in Taiwan. 


\section{Table 2}

Summary of TSG Projects

Hidden Dragon (not being seen) phrase

Project I-1: 2010.9-2011.1: Conduct Students and Faculty Survey

Sponsor: NCUE.

Coordinator: NCUE Office of Academic Affairs, NCUE as first-line executive disciplined by TMOE.

Participants: NCUE students and faculty in 66 academic programs.

TMOE's requirements: conduct students and faculty survey about career planning and curriculum feedback to examine those programs' accountability in term of students' employability.

Our extra achievement: (1) incorporating the $0^{*} \mathrm{NET}$ content model and assessments into the survey questionnaire, which resulted in the $0^{*} \mathrm{NET}$ Knowledge Inventory; and (2) constructing Consummate Career Inventory. We also took advantage of TMOE's policy to develop CCN grounding parts.

Our strategy: give premiums coupons, that is, cooperate and volunteer for TMOE requested tasks for NCUE Office; meanwhile, accomplish something other than what TMOE expected.

Project I-2: 2011.1-2012.12: Conduct Alumni Survey and Curriculum Development System

Sponsor: NCUE, with support from the TMOE.

Coordinator: NCUE Office of Alumni Services, as first-line executive disciplined by TMOE.

Participants: NCUE alumni in 66 academic programs.

TMOE's requirements: (1) conduct an alumni survey about their curriculum feedback; (2) develop the Curriculum Development System to integrate alumni feedback into curriculum revision; (3) use the results from the above two to examine academic programs' accountability in term of students' employability.

Our extra achievement: (1) incorporate the 0*NET content model and assessments into the survey questionnaire, which resulted in tools for career vision, such as the 0*NET Skill Inventory and 0*NET Work Activities Inventory; (2) construct tools for projecting strategies such as career unfolding style, career unfolding capacity, and career beliefs of learning and working; (3) set up the CCN Career Path Exploration Module and the CCN Quantitative Evaluation Module; and (4) reconstruct the Curriculum Mapping Platform to connect with Curriculum Development System and CCN. We also took advantage of TMOE's policy to set up CCN grounding parts.

Our strategy: the same as Project I-1.

Visible Dragon (being seen) phrase

Project II-1: 2012.3-2012.12: Establish CCN Sky-touching parts

Sponsor: NCUE.

Coordinator: NCUE School of Education, as first-line executive disciplined by the TMOE.

Participants: a consultative committee of 13 career experts from various places in Taiwan.

TMOE's requirements: set up some sort of precision instruments to help our university pass TMOE's program evaluation.

Our Extra Achievement: establish two CCN sky-touching parts, CCN Narrative Sharing Module and CCN Qualitative Assessment Module Our Strategy: barter grounding parts for sky-touching parts, that is, volunteer to set up a website, which includes the CCN Career Path Exploration Module, CCN Quantitative Evaluation Module, and CCN Qualitative Assessment Module, that could fulfill TMOE's program evaluation criteria.

Project II-2: 2012.8-2012.12: Compete with NCUE managers for next year's funding

Sponsor: NCUE, with support from the TMOE

Coordinator: NCUE top managers, as first-line executive disciplined by the TMOE.

Participants: NCUE executives.

TMOE's requirements: provide career services using the UCAN.

Our extra achievement: obtain funding for the first TSG service project with the CCN.

Our strategy: barter academic credits of the CCN grounding parts for TSG service projects fund, that is, persuade NCUE management that CCN and TSG service projects can make the NCUE's teaching excellence programs look better from TMOE's perspective.

\section{Diligent Dragon (working hard to excel) phase}

Project III-1: 2013.1-2014.12: Develop career development teaching materials and services

Sponsor: NCUE, with support from the TMOE.

Coordinator: NCUE Office of Student Affairs, as first-line executive, disciplined by the TMOE.

Participants: 106 students from the NCUE who freely registered to participate.

TMOE's requirements: adminiser UCAN assessments and connect test results to a learning plan.

Our extra achievement: develop a two-credit college-level career development course and a series of 10 career development workshops, all of which apply TSG guidelines and utilise CCN resources.

Our strategy: compete with political power by professional power from decent professional work, that is, use extra hard work to improve competitiveness of TSG teaching materials and training.

Project III-2: 2013.6-2014.12: Develop professional resources and methods for career services

Sponsor: Tainan Bureau of Education.

Coordinator: Tainan Bureau of Education and its junior high schools, as first-line executive, disciplined by the TMOE.

Participants: about 150 school counsellors and 20,000 students from 78 Tainan junior high schools for the first year; about 50 volunteering school counsellors for the second year

TMOE's requirements: administer vocational interest assessments and connect one's test results to high school choice.

Our extra accomplishment: develop a model to initiate local teaching materials development and a model for local practitioners training, all of which are needed for TSG service projects.

Our strategy: compete with political power by professional power from professional work. 
Table 2

Continued

Jumping Dragon (evolving to be great) phrase

Project IV-1: 2013.6-2013.12: Develop career activity design and teaching materials for career services

Sponsor: TMOE

Coordinator: TMOE's Youth Development Administration, as top executive, disciplined by TMOE

Participants: about 10 practitioners and 300 students in 6 Taiwanese universities

TMOE's requirements: provide career services using the UCAN

Our extra accomplishment: develop a 5-themes 18-unit college-level career development teaching materials appropriate for all Taiwanese

universities

Our strategy: guide trend along its natural course of development

Project IV-2: 2013.1-2013.12: Promote career teaching materials and an allied website for Taiwanese universities

Sponsor: TMOE

Coordinator: TMOE's Department of Higher Education, as top executive, disciplined by TMOE

Participants: about 60 practitioners and 500 students in 20 Taiwanese universities

TMOE's requirements: provide career services using the UCAN

Our extra accomplishment: develop an allied website of YoungEagle-CCN-CVHS as well as a database of teaching materials and a model to

initiate local teaching materials development and practitioners training for universities

Our strategy: guide trend along its natural course of development

Note: NCUE is the workplace of the first three authors; NCUE's TE programs: NCUE's teaching excellence programs sponsored by TMOE; CCRC: NCUE's Chinese Career Research Center; TSG: our TSG model and guidelines; PEF: person-environment fit.

We collected quantitative and qualitative data from each service project, including participants' activity products or homework completed in the process, as well as outcome measures and feedback questionnaires at the end. These data were used to provide information about the five interconnectedness indexes.

\section{Results}

This section presents the followings: (1) actions and effective social action strategies from the Classic of Changes; (2) functions of the $\mathrm{CCN}$ as a useful product from earlier projects and resources for later projects; and (3) effectiveness of this research in terms of five interconnectedness indexes (Liu et al., 2008).

\section{Actions and Effective Social Action Strategies From the Classic of Changes}

To break through the TMOE's domination, this research effectively applied yin-yang alternation principles and action strategies derived from four stages of chien from Classic of Changes. We utilised both yin strategies of rolling with the punches and yang strategies of guiding a trend along its natural course of development. These strategies were adopted when the opportunity presented itself and were combined with flexibility and creativity throughout our research process.

Table 2 summarises actions in our research, including the execution periods, sponsors, coordinators, participants, TMOE's requirements, and our extra achievements, as well as our social action strategies. Detailed descriptions of actions and action strategies of each phase will be presented next.

The hidden dragon phase. We knew we were underdogs compared to the TMOE. Without political and economic resources, we creatively utilised yin strategies; for exam- ple, giving coupons to coordinators to achieve our goals. We volunteered to assist with several surveys in order to assist our university to fulfill the TMOE's requirements. Taking this chance, we incorporated the O*NET (the Occupational Information Net) content model into survey questionnaires, which became the foundation of the CCN Quantitative Evaluation Module.

During this process, the Chinese Career Research Center grew as a hidden dragon, avoiding the challenges from political power with the strategy of appreciating and adapting. The initial following and going along with governmental policies was turned into the foundation of building up the grounding parts of the CCN. Also, the survey data sets alone within the O*NET data sets became the bases in further developing three cyber systems, the CCN Career Path Exploration Module, Curriculum Development System, and Curriculum Mapping Platform. These three tightly connected cyber systems together provided internet resources needed for our career services for the NCUE.

The visible dragon phase. The tasks of this phase were to make ourselves be seen and to gain support. Like a process of bartering, we used previously established CCN grounding parts to generate the opportunity to touch the sky. The academic publications of the CCN Career Path Exploration Module and Quantitative Evaluation Module were recognised by the NCUE College of Education; and the Chinese Career Research Center's proposal was approved as a college-level research project. Hence, there was funding for the CCN touching-the-sky parts, including the CCN Qualitative Exploration Module and the Narrative Sharing Module.

Another important event in winning recognition from higher authorities was how we faced the challenge from the NCUE management. Some NCUE top managers preferred to use the UCAN. They argued that using the UCAN can save research funding and fulfills TMOE requirements. 
The first author talked to those managers directly and asked for a fair opportunity to demonstrate the quality and value of the $\mathrm{CCN}$, from the perspective of students' benefit and career profession rather than political considerations.

In the crucial panel discussion, we pointed out the values of the CCN from the TMOE's person-environment fit perspective. We argued for the following points: (1) O*NET datasets, established via rigorous assessment (Hubbard et al., 2000), could provide much more concrete and precise numerical information than the all-word no-number UCAN occupational information system. (2) The competence assessed by the UCAN inventory was restricted to particular occupations, which was suitable for the goal of occupational training, but not higher education. On the contrary, the O*NET content model (Peterson et al., 2001) has been developed to identify key descriptors suitable for cross-occupation comparisons. Hence, the O*NET competence framework could better guide students to focus on what could be applied or transferred to various jobs. (3) The O*NET has developed a crosswalk between its occupation classification system and classification of instructional programs (Kotamraju \& Steuernagel, 2012); hence, it created a good connection between higher education and the world of work. We concluded that, for the purpose of graduates' sustainable employability, rather than immediate employability or immediate employment, the CCN using the $\mathrm{O}^{*} \mathrm{NET}$ content model and database would definitely be a better career resource than UCAN.

With power derived from expertise rather than politics, we changed the attitudes of the NCUE management. We persuaded NCUE management that the CCN and a TSG service project could make NCUE's teaching excellence programs obtain good reviews from the TMOE's perspective. Therefore, the NCUE management decided to support the promotion of the UCAN and the CCN on campus at the same time. They also provided funding to: (a) build a platform to further integrate $\mathrm{CCN}$, the Curriculum Development System, Curriculum Mapping Platform, and e-portfolio System; and (b) conduct a TSG service project to develop and promote career development teaching materials and services. In addition, our negotiation process was reframed and respected by the NCUE management as a good professional effort to protect and advocate for our profession.

At the end of this phase, our TSG model and the CCN had already evolved to become useful resources for the NCUE's career programs. The satisfactory results helped our university secure TMOE's Excellent Teaching Funds for 2 more years. Hence, the NCUE started to fund the $\mathrm{CCN}$ and the first TSG service project. This also opened the door for the TMOE to become familiar with the CCN and TSG service projects in the next phase.

The diligent dragon phase. Hard work - doing more than was required - was the main characteristic of this phase. While the first two phases focused on establishing inventories and cyber systems, this phase was devoted to career service projects. For Project III-1, the TMOE required all universities in Taiwan to administrate UCAN assessments and connect students' test results to their learning plan; we developed career development teaching materials using CCN assessments and connected students' test results to their career projecting. We did similar things in Project III-2. Moreover, in both projects, we took one step further to make a close connection between those teaching materials and their theoretical foundation, our TSG model and the TSG guidelines. That is, we developed the theory and the practical materials at the same time. Lewin's (1946) cyclical-spiral process of planning, acting, and evaluating was applied. This extra-diligent hard work was what made our projects part of an action research rather than simple career services.

In Project III-1, we developed a two-credit, collegelevel elective course utilising CCN and TSG guidelines. The main goal of this course was to facilitate college students to develop their own touching the sky yet grounded projecting strategies to explore their self-identification and actualise their career visions. In spring 2013, 36 students took the course. Based on these students' classroom activity and homework performance as well as learning notes, our TSG model and guidelines, the CCN and teaching materials were revised. In spring 2014, 18 students took the course; the corresponding revision was processed again.

In fall 2013, we transferred the abovementioned teaching materials into a series of 10 career development workshops. Each workshop included 1-hour online assessment and 2-hour exploration activities. There were 55 students in those workshops. Based on their workshop performance and feedback questionnaires, our TSG model and guidelines, and the CCN and teaching materials were revised again.

In Project III-2, we expanded our services to 78 junior high schools in Tainan City, Taiwan. The major missions of this project included CCN services, inventories revision, professional counsellor training, and teaching materials development. All these were done to fulfill TSG guidelines and TMOE policies at the same time. In other words, our TSG model was utilised to complete the TMOE's fit model.

In June 2013, a Tainan student counselling centre invited their managers and executives, as well as school presidents and counsellors from junior high schools, to establish a consultative committee that served as the executive team to carry out Lewin's (1946) cyclical-spiral process. After an explanation session for the top managers of Tainan junior high schools, inventories of vocational interest, career unfolding style, career unfolding capacity and career status were administered to junior high school students, these test results, along with career development activities applying the $\mathrm{CCN}$, were delivered by school counsellors. We also held a teaching materials competition and selected 20 pieces from 64 submitted projects. At the end of 2013, an investigation report and four 
outstanding pieces of teaching materials were presented in an achievement exhibition.

In February 2014, the consultative committee made a rigorous examination of progress in the first year and identified two crucial problems: (1) most school counsellors did not possess sufficient knowledge of our TSG model so they could not make good use of the CCN resources; and (2) the CCN was not user friendly for junior high school students. Hence, we set up two teams of volunteer school counsellors to improve teaching materials and website design, respectively. In summer 2014, work by the two teams was developed into a school counsellors' training workshop and a specialised route for junior high school students to use the CCN. We are looking forward to the improved results after the tryout in autumn 2014.

During this stage, professional work was utilised to win external recognition and resources. In total, we developed three sets of career development teaching materials, a local teaching materials development model, and a local practitioners' professional training model.

The jumping dragon phase. As jumping dragons, we worked hard to obtain further development and influence by: (1) promoting career services that applied our TSG model and guidelines and utilised CCN resources, and (2) improving the TSG model and guidelines, the CCN, corresponding teaching materials and the training model with Lewin's (1946) cyclical-spiral process. This phase had two national service projects. The VI-1 project developed five themed, 18-unit, college-level career development teaching materials applicable for all Taiwanese universities; the second project promoted the abovementioned teaching materials and the $\mathrm{CCN}$ to 20 universities. The method and processes of Project VI-2 were similar to that of Project VI-1. In sum, our effort not only changed potential users' P-E fit career mindset, but also gained support and funds from the TMOE. The YoungEagle-CCN-CVHS alliance has made our work much more influential and brought about further social changes (see Wang, Shiah-hou, Wu, \& Liu, 2014).

\section{Functions of a TSG Career Website: Chinese Career Net}

The CCN is a TSG-based website (Chen, S. Liu, Deng, Yang, \& Lee, 2013; S. Liu, Deng, \& Wang, 2011; S. Liu et al., 2011; Lu et al., 2013) that contains factual and narrative occupational information as well as quantitative and qualitative measures. It serves as a career resources centre with both rational and intuitive information and assistance.

For the rational person-environment fit of choosing and controlling, which is also adopted by the UCAN, the $\mathrm{CCN}$ provides quantitative assessment and objective factual academic major and occupational information from the O*NET (Hubbard et al., 2000; National Center for O*NET Development, 2006; Peterson, Mumford, Borman, Jeanneret, \& Fleishman, 1999; Peterson et al., 2001; Rounds, Armstrong, Liao, Lewis, \& Rivkin, 2008;
Rounds, Armstrong, Liao, Rivkin, \& Lewis, 2008). The assessments include tools for career visions (e.g., career interest, work value, knowledge, skill, and work activity) and for projecting strategies and status (e.g., career unfolding style, career unfolding capacity, career beliefs regarding learning and working, consummate careers; S. Liu, Chen, Lu, \& Ching, 2014). Data on career interest, work value, knowledge, skills, work style, and work activity can be found for 855 occupations and 123 academic programs.

In addition, for intuitive exploration of appreciating and adapting, which is not included in the UCAN, the CCN provides: (1) a personal database, (2) a multi-search engine for path exploration, (3) a personal diary of quantitative assessment, and (4) qualitative exploration with information integration. Finally, this website also includes two message board sections titled Narrative Sharing and Professional Sharing as networking platforms for users to post personal reflections and professional information, respectively.

\section{Action Effects: Interconnectedness}

The purpose of this research was to break through the TMOE's domination over career service and education, rather than examining the intrinsic quality of our service projects. During the past 4 years, starting from 'political wrongness' and no resources at all, we have achieved eight projects, the TSG model and guidelines, the CCN, several sets of teaching materials, a professional training model, and direct funding from TMOE. Such huge progress demonstrates our success in breaking through the TMOE's domination. To provide even more evidence of the research outcome, we used Liu et al.'s (2008) interconnectedness indexes.

As described in Research Framework and Process, constant feedback was acquired in a cyclical-spiral process of planning, action, and evaluation. Feedback from coordinators and participants of all the TSG service projects facilitated the development of the TSG theory and practices. The research process and progress show that this research is evolving, and our team is continually renewed.

Reflexivity was related to students changing their career view and becoming passionate about career exploration and education. For example, many students mentioned their revived passion for their future, excitement about career exploration, and confidence about pursuing future careers. Some of them even offered to promote future workshops for their schoolmates.

Empowerment was observed when school counsellors discovered that the TSG approach was much more in line with reality than the modernistic linear approach they were used to. Although they knew the linear approach was not working well for them or their students, they did not know of other alternatives until then. It is promising that more than 20 high school counsellors and about 70 faculty 
members from our workshops have started to build their own TSG curriculum.

In terms of social relation-building, our team included researchers and practitioners from Taiwan, Malaysia, and China. More important was that local teams were formed and took the lead in each service project. Together we worked through the TMOE's domination and gained their support. Furthermore, the establishment of the YoungEagle-CCN-CVHS alliance was another indication of social relation-building.

There was evidence for social changes as well: (1) counsellors started to expand their career views and to develop curricula with TSG perspectives, and (2) students also expanded their career views and became excited about creating and actualising their career visions instead of feeling dragged along. In addition, the TMOE's view of our TSG model and the CCN has changed from sceptical to supportive. They have since started to put money into TSG service projects directly. Given the TMOE's domination in promoting a person-environment fit paradigm at the beginning, this is a huge social change. Furthermore, our success in promoting the Chinese philosophy-based TSG model and its applications also echoes Hwang's (2005, 2012) advocacy for culture-inclusive psychology, as well as Liu, Ng, Gastardo-Conaco and Wong's (2008) advocacy for action research.

\section{Future Vision: A Host of Dragons Without any Leader}

With the progress and completion of the CCN and TSG projects, this action study has challenged TMOE policies successfully. From the results of four ongoing TSG service projects, we see the acceptance and enthusiasm for applying yin-yang alternation principles to career development.

The person-environment fit paradigm of career development still dominates in Taiwan and many other Asian and non-Asian countries (Spokane et al., 2000; Tinsley, 2000; Tracey et al., 2000). This culture-based career model provides a good alternative for people of Chinese descent to face this fast-paced world. According to the wisdom of chien in the Classic of Changes, a host of dragons without any leader is the best vision of dragon-growing (Chen, 2002; Fu, 1981; Fu, 2011; S. Liu, 2005). Hence, the Chinese Career Research Center has been helping local teams use TSG service projects to become grown-up dragons as well. This article shares our experience to encourage more researchers in various Asian cultures to develop their own culture-inclusive career theories and practice as a global enterprise.

\section{Acknowledgments}

This article was based on the following projects: (1) a research project sponsored by National Changhua University of Education (NCUE, 2010.9.1 2010.12.31); (2) a NCUE Teaching Excellence Project sponsored by Taiwan Ministry of Education (TMOE) (2011.1.1 2012.12.31); (3) a NCUE Teaching Excellence Project sponsored by TMOE (2011.1.1 2012.12.31); (4) a service project sponsored by Tainan Education Bureau, Taiwan (2013.6.1 2013.12.31); (5) a NCUE academic development project sponsored by NCUE (2012.3.1 2012.12.31); (6) a NCUE Teaching Excellence Project sponsored by TMOE (2013.1.1. 2014.12.31); (7) a University of Taipei Project sponsored by TMOE (20137.1 2014.12.31); (8) a National Sun Yat-sen University Teaching Resources Sharing Project sponsored by TMOE (2013.10.1 2014.12.31); (9) a personal project sponsored by Taiwan Ministry of Science and Technology (NSC 102-2410-H-034-005) (2013.8.1 2014.12.31).

\section{References}

Adams, M. (2006). Towards an existential phenomenological model of life span human development. Existential Analysis, 17(2), 261-280.

Atsumi, T. (2007). Aviation with fraternal twin wings over the Asian context: Using nomothetic epistemic and narrative design paradigms in social psychology. Asian Journal of Social Psychology, 10, 32-40.

Bardi, A., Guerra, V.M., \& Ramdeny, G.S.D. (2009). Openness and ambiguity intolerance: Their differential relations to well-being in the context of an academic life transition. Personality and Individual Differences, 47(3), 219-223. doi:10.1016/j.paid.2009.03.003

Bredemeier, K., \& Berenbaum, H. (2008). Intolerance of uncertainty and perceived threat. Behaviour Research and Therapy, 46(1), 28-38. doi:10.1016/j.brat.2007.09.006

Bright, J.E.H., \& Pryor, R.G.L. (2005). The chaos theory of careers: A users guide. Career Development Quarterly, 53, 291305.

Bright, J.E.H., \& Pryor, R.G.L. (2007). Chaotic careers assessment: How constructivist and psychometric techniques can be integrated into work and life decision making. Career Planning and Adult Development Journal, 23(2), 34-45.

Bussolari, C.J., \& Goodell, J.A. (2009). Chaos theory as a model for life transitions counseling: Nonlinear dynamics and life's changes. Journal of Counseling \& Development, 87, 98-107.

Chen, C. (2002). Introduction to 'Yi Zhangju'. Jinan: Chi-lu.

Chen, Y., Liu, S., Deng, C., Yang, Y., \& Lee, H. (2013). Rational and intuitive CCN Vocational Card Sort: Practical applications with career information and guidance cyber system. Taiwan Counseling Quarterly, 5(2), 28-50.

Cheng, C. (2009). Paradigm of change (Yi) in classical Chinese philosophy: Part I. Journal of Chinese Philosophy, 36(4), 516530 .

Forrier, A., Sels, L., \& Stynen, D. (2009). Career mobility at the intersection between agent and structure: A conceptual model. Journal of Occupational \& Organizational Psychology, 82(4), 739-759.

Fu, L. (1981). Interpretations of 'Zhou Yi'. Taipei: Commercial.

Fu, P. (2011). Be content with what one is: Fu, P. on 'Classic of Changes'. Taipei: Commonwealth.

Gelatt, H.B. (1989). Positive uncertainty: A new decision-making framework for counseling. Journal of Counseling Psychology, $36,252-256$. 
Gelatt, H.B. (1991a). Creative decision making using positive uncertainty. Los Altos, CA: Crisp.

Gelatt, H.B. (1991b). Positive uncertainty: A paradoxical philosophy of counseling whose time has come. Retrieved from ERIC database. (ED347486)

Gelatt, H.B. (1992). A new vision for counseling. Counseling and Human Development, 25(1), 1-10.

Gelatt, H.B. (1995). Chaos and compassion. Counseling and Values, 39(2), 108-116.

Gelatt, H.B., \& Gelatt, C. (2003). The power of positive uncertainty: Making creative career decisions. Retrieved from ERIC database. (ED 480 506)

Harrison, R. (2006). From landlines to cell phones: negotiating identity positions in new career contexts. Journal of Employment Counseling, 43, 18-30.

Hsiao, C. (2006). Constructing of and pursuing happiness in career-life course (Unpublished master's thesis). National Changhua University of Education, Taiwan.

Huang, C. (2003). Interpretations of 'One Yin and One Yang are called Tao'. Legein Monthly, 29(3), 17-19.

Huang, C. (2007). New translation of 'the interpretation of ChienKun'. Taipei: Sanmin.

Hubbard, M., McCloy, R., Campbell, J., Nottingham, J., Lewis, P., Rivkin, D., \& Levine, J. (2000). Revision of $O^{*}$ NET data collection instruments. Raleigh, NC: National Center for O*NET Development.

Hubbard, M., McCloy, R., Campbell, J., Nottingham, J., Lewis, P., Rivkin, D., \& Levine, J. (2000). Revision of $O^{*} N E T$ data collection instruments. Raleigh, NC: The National Center for $\mathrm{O} *$ NET Development. Retrieved from http://www.onetcenter.org/dl_files/Data_appnd.pdf

Hwang, K. (2005). A philosophical reflection on the epistemology and methodology of indigenous psychologies. Asian Journal of Social Psychology, 8(1), 5-17. doi:10.1111/j.1467839X.2005.00153.x

Hwang, K.K. (2012). Foundations of Chinese psychology: Confucian social relations. New York: Springer.

Hwang, K.K. (2013a). Linking science to culture: Challenge to psychologists. Social Epistemology, 27(1), 105-122.

Hwang, K.K. (2013b). The construction of culture-inclusive theories by multiple philosophical paradigms. Social Epistemology Review and Reply Collective, 2(7), 46-58.

Kao, H., \& Liu, S. (2012). Construction and analysis of the Inventory of Career Uncertainty for Senior High School Students. Global Mental Health E-Journal, 3(1), 1-27.

Kotamraju, P., \& Steuernagel, B. (2012). Crosswalk validation project: Final report. Louisville, KY: Research Center for Career and Technical Education.

Krumboltz, J.D. (2009). The happenstance learning theory. Journal of Career Assessment, 17, 135-154.

Lee, Y. (2010). 'Cocoon-breaking': The existence of passion. (Unpublished master's thesis). National Changhua University of Education, Taiwan.

Lewin, K. (1946). Action research and minority problems. Journal of Social Issues, 2, 34-46.
Liu, J.H. (2014). What Confucian philosophy means for Chinese and Asian psychology today: Indigenous roots for a psychology of social change. Journal of Pacific Rim Psychology, 8(2), $35-42$.

Liu, J.H., Ng, S.H., Gastardo-Conaco, M.C., \& Wong, D.S.W. (2008). Action research: A missing component in the emergence of social and cross-cultural psychology as a fully inter-connected global enterprise. Social and Personality Psychology Compass, 2/3, 1162-1181. doi:10.1111/j.17519004.2008.00100.x

Liu, S. (1999). Career view of ordinary persons: College students in Taiwan as an example. In Chinese Guidance Association (Ed.), Trend of guidance (pp. 573-602). Taipei: Wunan.

Liu, S. (2005). A holistic career development model. Presented in the proceedings of holistic guidance and counseling training conference. Changhua, Taiwan: Department of Guidance and Counseling, National Changhua University of Education.

Liu, S., Chen, Y., Lu, L., Lu, Y., \& Ching, S., (2014). Existential phenomenological career guidance: Teaching design and teaching materials for Malaysia high school. Guidance Quarterly.

Liu, S., \& Chu, H. (1999). The relationship among decisionmaking style, coping with uncertainty, and career satisfaction in college students. Proceedings of the National Science Council, 9(3), 448-473.

Liu, S., Deng, C., \& Wang, C. (2011, July). Life-and-culturecentered career counseling. Paper presented at the Third Forum of the Cross-Strait Four Regions of Higher Education Psychological Counselling and Consultation, Macau University of Science and Technology, Macau.

Liu, S., \& Wang, C. (2014). The career model touching-the-sky yet grounded: The theoretical base of Chinese Career Net. Taiwan Counseling Quarterly, 6(1), 76-87.

Liu, S., \& Wang, C., Chen, Y., Deng, C., Yang, Y., Lin, M., Su, F., \& Lu, Y. (2013, June). CCN Career Unfording Style Inventory: Construction and application. Paper presented at the Fifth Forum of the Cross-Strait Four Regions of Higher Education Psychological Counselling and Consultation, Shanghai Ocean University, Shanghai.

Liu, S., Wang, C., Deng, C., Wang, S., Li, H., \& Huang, J. (2011, February). The establishment and application of a career information and assistance cyber system with rationality and intuition: Chinese Career Net as an example. Paper presented at the Congress of Psychotherapy and Mental Health in Taiwan, Shin Chien University, Taipei.

Liu, Y. (2005). Introduction to 'Zhou-Yi Interpretation'. Jinan: Chi-lu.

Lu, Y., Wang, S., Liu, S., Chang, Y., Wu, P., \& Chen, J. (2013). CCN Interest Inventory: An online system of administration and interpretation within career information and guidance cyber system. Taiwan Counseling Quarterly, 5, 1-16. Retrieved from http://tcq.heart.net.tw/article/TCQ5-1-1.pdf

Mendes, P., \& Moslehuddin, B. (2006). From dependence to interdependence: towards better outcomes for young people leaving state care. Child Abuse Review, 15(2), 110-126. doi:10.1002/car.932 
Miller, M.J. (1995). A case for uncertainty in career counseling. Counseling and Values, 39, 162-168.

Mitchell, K.E., Levin, A.S., \& Krumboltz, J.D. (1999). Planned happenstance: Constructing unexpected career opportunities. Journal of Counseling \& Development, 77, 115-124.

Nan, H. (1991a). Lectures on 'Great Appendix' (vol. 1). Taipei: Old Culture.

Nan, H. (1991b). Lectures on 'Great Appendix' (vol. 2). Taipei: Old Culture.

National Center for O*NET Development, (2006). New and emerging (N\&E) occupations methodology development report. Washington, DC: U.S. Department of Labor.

Peng, H., Hung, J., Lin, C., \& Liu, S. (2013). Concept research of career resilience: The career narrative in the secondary data analysis. Taiwan Counseling Quarterly, 5(1), 17-43.

Peng, H., Hung, J., \& Liu, S. (2013, August). A phenomenological inquiry on career resilience experience. Paper presented at the Eighth Chinese Psychologist Conference, Beijing Normal University, Beijing.

Peterson, et al. (2001). Understanding work using the Occupational Information Network $\left(\mathrm{O}^{*} \mathrm{NET}\right)$ : Implications for practice and research. Personnel Psychology, 54, 451-492. doi:10.1111/j.1744-6570.2001.tb00100.x

Peterson, N.G., Mumford, M.D., Borman, W.C., Jeanneret, P.R., \& Fleishman, E.A. (Eds.). (1999). An occupational information system for the 21st century: The development of O* NET. Washington, DC: American Psychological Association.

Peterson, N.G., Mumford, M.D., Borman, W.C., Jeanneret, P.R., Fleishman, E.A., Levin, K.Y., ... Dye, D.M. (2001). Understanding work using the Occupational Information Network (O*NET). Implication for practice and research. Personnel Psychology, 54, 451-492. doi:10.1111/j.17446570.2001.tb00100.x

Pryor, R.G.L., Aniundson, N.E., \& Bright, J.E.H. (2008). Probabilities and possibilities: The strategic counseling implications of the chaos theory of careers. The Career Development Quarterly, 56, 309-318.

Pryor, R.G.L., \& Bright, J.E.H. (2003a). The chaos theory of career. Australian Journal of Career Development, 12(3), 1220.

Pryor, R.G.L., \& Bright, J.E.H. (2003b). Order and chaos: A twenty-first century formulation of careers. Australian Journal of Psychology, 55(2), 121-128.

Pryor, R.G.L., \& Bright, J.E.H. (2004). 'I had seen order and chaos but had thought they were different': Challenges of the chaos theory for career development. Australian Journal of Career Development, 13(3), 18-22.

Pryor, R.G.L., \& Bright, J.E.H. (2005). Chaos in practice: Techniques for career counsellors. Australian Journal of Career Development, 14(1), 18-29.

Pryor, R.G.L., \& Bright, J.E.H. (2006). Counseling chaos: Techniques for counselors. Journal of Employment Counseling, 43(1), 2-17.

Pryor, R.G.L., \& Bright, J.E.H. (2007). Applying chaos theory to careers: Attraction and attractors. Journal of Vocational Behavior, 71, 375-400.
Pryor, R.G.L., \& Bright, J.E.H. (2008). Archetypal narratives in career counselling: A chaos theory application. International Journal of Educational and Vocational Guidance, 8, 7182.

Pryor, R.G.L., \& Bright, J.E.H. (2009). Game as a career metaphor: A chaos theory career counseling application. British Journal of Guidance \& Counselling, 37(1), 3950.

Pryor, R.G.L. (2007). Assessing complexity: Integrating being and becoming. Journal of Employment Counseling, 44, 126134.

Reindal, S.M. (1999). Independence, dependence, interdependence: Some reflections on the subject and personal autonomy. Disability \& Society, 14(3), 353-367.

Rounds, J., Armstrong, P., Liao, H., Lewis, P., \& Rivkin, D. (2008). Second generation occupational interest profiles for the O*NET system: Summary. Raleigh, NC: The National Center for O*NET Development. Retrieved from http:// www.onetcenter.org/dl_files/SecondOIP_Summary.pdf

Rounds, J., Armstrong, P., Liao, H., Rivkin, D., \& Lewis, P. (2008). second generation occupational value profiles for the O*NET system: Summary. Raleigh, NC: The National Center for O*NET Development. Retrieved from http:// www.onetcenter.org/dl_files/SecondOIP_Summary.pdf

Samuels, G.M., \& Pryce, J.M. (2008). 'What doesn't kill you makes you stronger': Survivalist self-reliance as resilience and risk among young adults aging out of foster care. Children and Youth Services Review, 30, 1198-1210. doi:10.1016/j.childyouth.2008.03.005

Spokane, A.R., Meir, E.I., \& Catalano, M. (2000). Personenvironment congruence and Holland's theory: A review and reconsideration. Journal of Vocational Behavior, 57(2), 137-187. doi:10.1006/jvbe.2000.1771

Stoltz, K.B., Wolff, L.A., Monroe, A.E., Mazahreh, L.G., \& Farris, H.R. (2013). Adaptability in the Work Life Task: Lifestyle, stress coping, and protean/boundaryless career attitudes. Journal of Individual Psychology, 69(1), 66-83.

Tinsley, H.E.A. (2000). The congruence myth: An analysis of the efficacy of the person-environment fit model. Journal of Vocational Behavior, 56, 147-179.

Tracey, T.J.G., Darcy, M., \& Kovalski, T.M. (2000). A closer look at person-environment fit. Journal of Vocational Behavior, 56(2), 216-224. doi:10.1006/jvbe.1999.1733

Trevor-Roberts, E. (2006). Are you sure? The role of uncertainty in career. Journal of Employment Counseling, 43(3), 98-116.

Vaughan, K., \& Roberts, J. (2007). Developing a 'productive' account of young people's transition perspectives. Journal of Education and Work, 20(2), 91-105. doi:10.1080/13639080701314621

Wang, S., Shiah-hou, H., Wu, C. \& Liu, C. (2014). Information system innovation as a social action: The case of career and vocational helping systems. Journal of Pacific Rim Psychology, $8(2), 71-82$.

Wijers, G., \& Meijers, F. (1996). Career guidance in the knowledge society. British Journal of Guidance and Counselling, 24(2), 185-198. 